\title{
Conceptual Design of Low-Boom Low-Drag Supersonic Transports
}

\author{
Yicheng Sun ${ }^{1}$ \\ Tsinghua University, Beijing, 100084, China \\ Howard Smith ${ }^{2}$ \\ Cranfield University, Bedfordshire, MK43 OAL, UK \\ Haixin $\mathrm{Chen}^{3}$ \\ Tsinghua University, Beijing, 100084, China
}

\begin{abstract}
This paper introduces a supersonic aircraft design model developed in a multidisciplinary design analysis and optimization (MDAO) environment. Low- to medium- fidelity methods are applied to the conceptual design model. A family of different classes supersonic aircraft are designed with similar general layout, including a single seat supersonic demonstrator, a 10-passenger supersonic business jet and a 50-seat supersonic airliner. These concepts prove the feasibility of low-boom low-drag supersonic transport designs in a multidisciplinary perspective. There are some challenges to balance the volume with packaging and control requirements. The low-boom design for configuration with nacelles are also very challenging.
\end{abstract}

\section{Nomenclature}

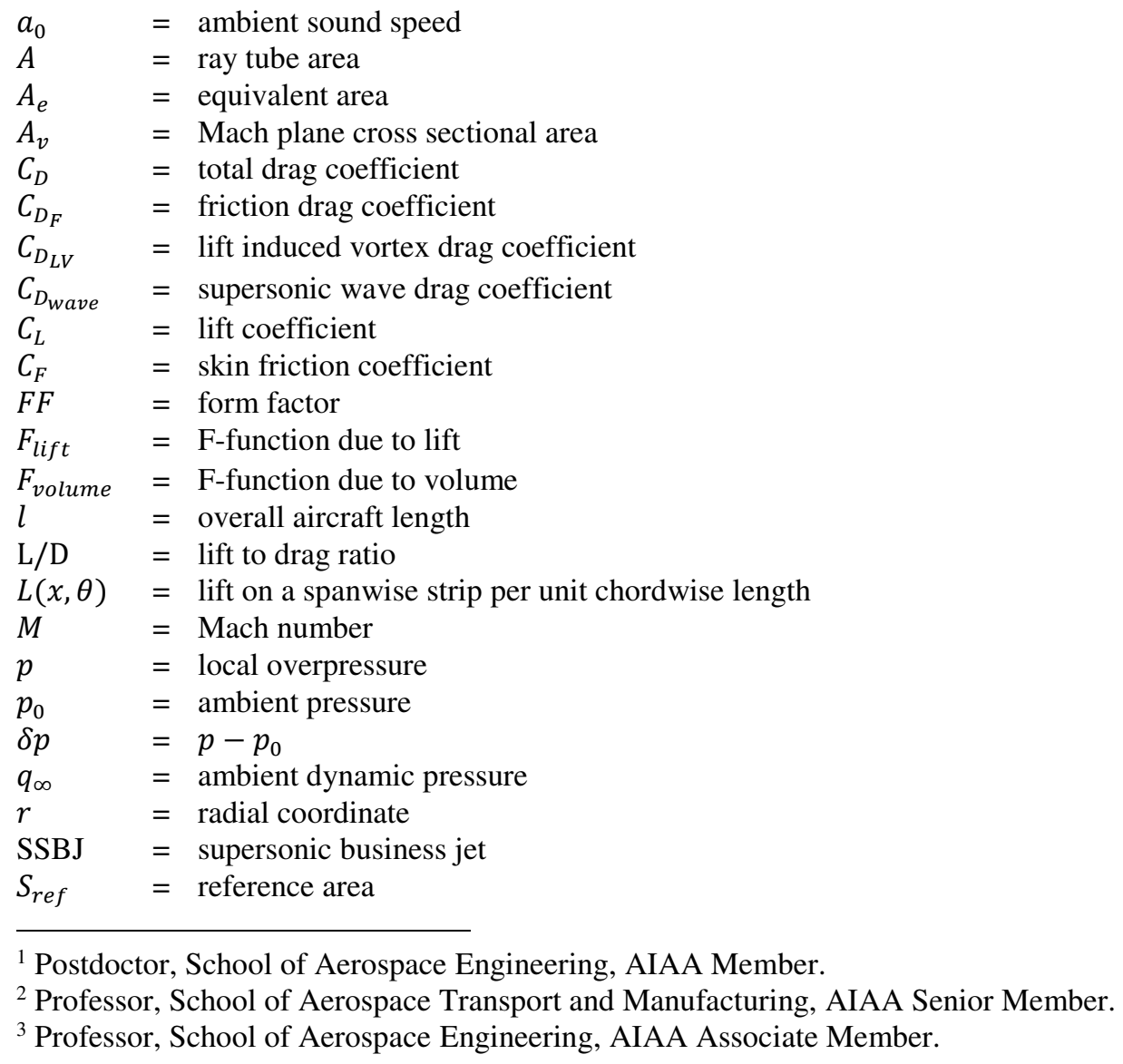




$\begin{array}{ll}S_{w e t} & =\text { wet area } \\ x & =\text { longitudinal axis location } \\ \beta & =\sqrt{M^{2}-1} \\ \gamma & =\text { ratio of specific heat } \\ \theta & =\text { angle between the Y-axis and a projection onto the Y-Z plane of a normal to the Mach plane } \\ \chi & =x-\beta r, \text { the location on the axis of the equivalent body of the Mach plane translated field point }\end{array}$

\section{Introduction}

$\mathrm{T}$

HERE has been a renewed interest to design an environmentally friendly, economically viable and technologically feasible civil supersonic transport. It is desirable for the next-generation supersonic transport to have not only low sonic boom level but also high fuel efficiency. There has been a progress in low-boom technology by tailoring the lift and volume distribution [1]. However, the future supersonic civil transport can be viable only if overland supersonic restrictions are relaxed or entirely lifted [2]. NASA is working on a single-seat quiet supersonic demonstrator X-59 [3] to prove the low-boom design technology and support the potential changes in FAA regulations. BOOM Technology is building a demonstrator XB-1 [4] to test the supersonic technologies.

The supersonic business jet (SSBJ) is regarded as the pioneer for the next-generation supersonic transport [5]. Aerion Supersonic [6] has been updating its supersonic natural laminar flow SSBJ concept AS-2 to get a higher cruise aerodynamic efficiency. Spike Aerospace [7] is developing a low-boom SSBJ concept with innovative digital cabin. There have been many studies focusing on the business class supersonic transport concepts [8-11].

The supersonic airliner will be a next-step after the civil supersonic market is reopen. BOOM Technology [12] is developing a 55-75 passenger supersonic aeroplane with business-class fares. JAXA has been conducting research and experiments on next-generation supersonic transports, including 36-50 passenger supersonic aircraft [13].

The research is conducted in a multidisciplinary design analysis optimization environment. In the previous studies, the authors established the multidisciplinary methodologies for supersonic transport [14], evaluated the sonic boom and aerodynamics of current supersonic transports [1, 15], and optimized the Cranfield E-5 supersonic business jet for low-boom and low-drag objectives [16]. This paper is a further study based on the previous research, designing a single-seat supersonic demonstrator, a 10-seat SSBJ concept and a 50-seat supersonic airliner concept with low-boom and low-drag features.

\section{Design Methods}

The supersonic transport model is developed in a conceptual design environment called GENUS [17]. It is the aim of the GENUS aircraft conceptual design environment is to provide a modular, flexible framework both for designers to use existing, and for researchers to develop new, or use existing methods for aerospace vehicle design. The environment can synthesize and analyse most aerospace vehicle concepts. The modules in GENUS are linked together tightly, which makes the multidisciplinary design analysis and optimization possible. GENUS has proven its capabilities through a solar UAV design [18], a hypersonic transport design [19], a blended-wing-body airliner design [20], a conventional airliner design [21] and a combat UAV design [22].

\section{A. Geometry}

The geometry parts are abstracted into lifting surface and body component arrays. The lifting surface array is then specified as a wing, horizontal tail, vertical tail or canard. The body component array is specified as a fuselage, engine pod, external tank or tail boom. In this way, the geometry module can represent most of the configurations.

\section{B. Mission}

The mission module specifies the flight requirements for a design. These requirements are derived from the market or customer specifications. They are assumed to be the appropriate initial requirements for environmentally friendly and economically viable supersonic transport.

\section{Mass}

The mass breakdown module provides a general framework for estimating the mass of various components of an aircraft. Another important function of this module is to decouple the mass components from the packaging module that uses them. At this stage, only empirical methods are used for SSBJ design. These empirical methods include Howe's mass prediction method [23], Raymer's mass prediction method [24], Torenbeek's method [8], Cranfield inhouse mass prediction method, etc. 


\section{Aerodynamics}

The main aerodynamic analysis tool is PANAIR [25]. PANAIR can predict inviscid subsonic and supersonic flows of arbitrary configurations by solving a linear partial differential equation numerically. For aerodynamic analysis, PANAIR can provide lift coefficients and induced drag coefficients. The drag components for supersonic flight is denoted by Eq. (1).

$$
C_{D}=C_{D_{F}}+C_{D_{\text {wave }}}+C_{D_{L V}}
$$

where $C_{D}$ is the total drag coefficient, $C_{D_{F}}$ is the friction drag coefficient, $C_{D_{\text {wave }}}$ is the supersonic wave drag coefficient, $C_{D_{L V}}$ is the lift induced vortex drag coefficient.

The form factor method [26] is modified to calculate the zero-lift skin friction and form drag. The result comes from the contribution of each component, as shown in Eq. (2).

$$
C_{D_{F}}=\sum_{j=1}^{N} \frac{F F_{j} C_{F_{j}} S_{w e t_{j}}}{S_{r e f}}
$$

where $\mathrm{N}$ is the number of components used to model the configuration, $F F_{j}$ is the form factor of component $j, C_{F_{j}}$ is the skin friction coefficient of component $j, S_{w_{e t}}$ is the wet area of component $j, S_{r e f}$ is the reference area of the total aircraft.

The supersonic area rule [27] is applied to calculate wave drag due to volume, as indicated in Eq. (3) and Eq. (4). For accurate wave drag calculation, the Mach plane cross sectional area intersecting with the geometry is required.

$$
\begin{gathered}
C_{D_{\text {wave }}}(\theta)=-\frac{1}{2 \pi} \int_{0}^{l} \int_{0}^{l} \mathrm{~A}^{\prime \prime}\left(x_{1}\right) \mathrm{A}^{\prime \prime}\left(x_{2}\right) \ln \left|x_{1}-x_{2}\right| \mathrm{d} x_{1} \mathrm{~d} x_{2} \\
C_{D_{\text {wave }}}=\frac{1}{2 \pi} \int_{0}^{2 \pi} C_{D_{\text {wave }}}(\theta) d \theta
\end{gathered}
$$

where $\theta$ is the angle between the $\mathrm{Y}$-axis and a projection onto the $\mathrm{Y}-\mathrm{Z}$ plane of a normal to the Mach plane, $l$ is the overall aircraft length, $A(x)$ is the ray tube area at longitudinal coordinate $x$.

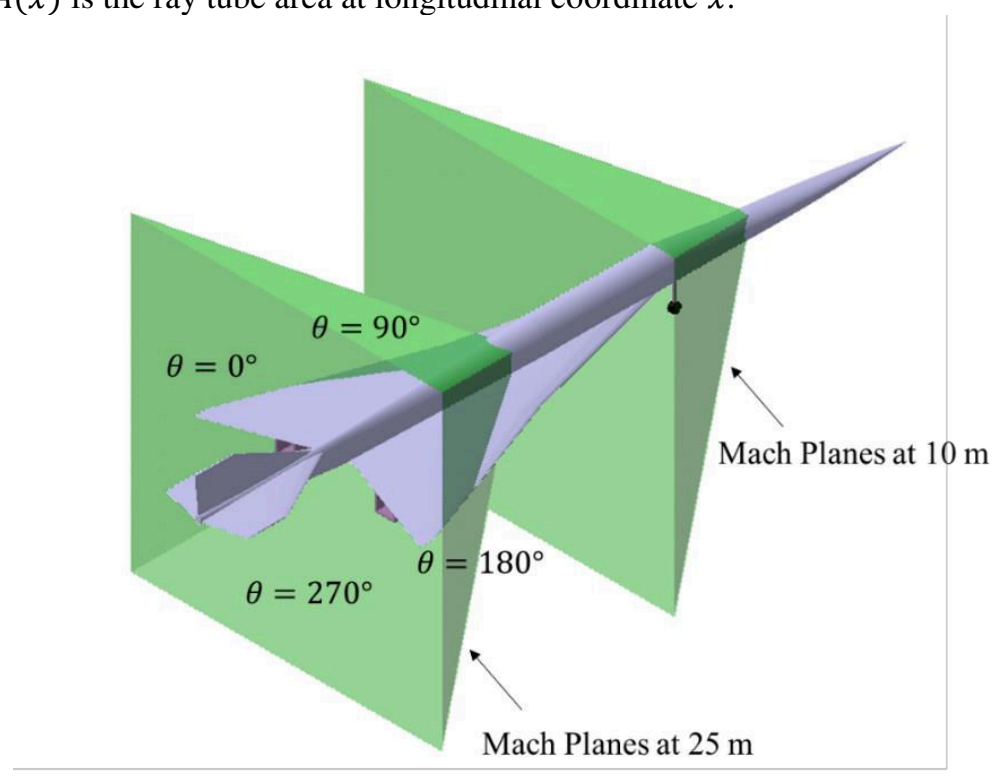

Fig. 1 Illustration of wave drag computing procedure

\section{E. Propulsion}

The propulsion module calculates the engine performance at any flight condition. The engine available thrust and corresponding specific fuel consumption (SFC) are stored in two matrices. Users can extract the engine performance at given flight condition by interpolating the Thrust-Mach-Altitude-Throttle matrix and the SFC-Mach-AltitudeThrottle matrix. The supersonic propulsion module uses the NASA EngineSim model [28] to build rubber engine 
system. EngineSim calculates the engine performance based on engine parameters, including the geometry, material property, flight condition, throttle setting and so on.

\section{F. Packaging and C.G.}

Packaging is a novel and essential module in the GENUS environment. The function of the packaging and CG module is, firstly, to position inner components to detect and avoid interference with other components and the external surface, secondly, to calculate the CG positions for various conditions (with and without fuel or payload). The CG positions are calculated by positioning the mass components from the mass module and they are then used for stability evaluation in this module.

\section{G. Performance}

The performance module is modified to be flexible for different segment combinations. Each segment consists of 11 control points by default. The Mach number, altitude, thrust request, aerodynamic coefficients, throttle, C.G. position, etc. at each point are calculated in a physical based approach. The time, distance, fuel consumption, flight path angle, etc. between every two points are calculated for field performance analysis.

\section{H. Stability and Control}

This module is designed to evaluate the stability characteristics and trim abilities of the aircraft at various flight conditions. Digital DATCOM [29] is an appropriate tool for stability and control analysis in aircraft conceptual design. The longitudinal and lateral-directional stability characteristics are provided by Digital DATCOM. High-lift devices and control characteristics can be calculated. Trim options are available for subsonic speeds.

\section{Sonic Boom Prediction}

In this research, there are two steps to predict the sonic boom intensity. The first step is to get the near-field pressure distribution. The second step is to propagate the near-field pressure to the ground through considering the nonlinear characteristics of the atmosphere.

The Whitham theory [30] is used for the near-field pressure calculation. The equivalent area due to volume and equivalent area due to lift are required for the near-field pressure calculation. The equation for the total effective area calculation is indicated in Eq. (5).

$$
A_{e}(x, \theta)=A_{v}(x, \theta)+\frac{\beta}{2 q_{\infty}} \int_{0}^{x} L(x, \theta) d x
$$

where $A_{e}(x, \theta)$ is the equivalent area at coordinate $x$ and angle $\theta, A_{v}(x, \theta)$ is the Mach plane cross sectional area at coordinate $x$ and angle $\theta, \beta=\sqrt{M^{2}-1}, q_{\infty}$ is the ambient dynamic pressure, $L(x, \theta)$ is the lift on a spanwise strip per unit chordwise length.

The F-function derives from the equivalent area, as shown in Eq. (6).

$$
F(x)=\frac{1}{2 \pi} \int_{0}^{x} \frac{A_{e}^{\prime \prime}(\bar{x}, \theta)}{\sqrt{x-\bar{x}}} d \bar{x}
$$

In this research, we decompose the F-function to F-function due to volume and F-function due to lift, as indicated by Eq. (7). This helps to study their individual effects on sonic boom intensity.

$$
F(x, \theta)=F_{\text {volume }}(x, \theta)+F_{\text {lift }}(x, \theta)=\frac{1}{2 \pi} \int_{0}^{x} \frac{A_{v}^{\prime \prime}(\bar{x}, \theta)}{\sqrt{x-\bar{x}}} d \bar{x}+\frac{\beta}{4 \pi q_{\infty}} \int_{0}^{x} \frac{L^{\prime}(\bar{x}, \theta)}{\sqrt{x-\bar{x}}} d \bar{x}
$$

where $F_{\text {volume }}$ is the F-function due to volume, $F_{\text {lift }}$ is the F-function due to lift.

The near-field pressure is then calculated based on the Whitham theory, as shown in Eq. (8).

$$
\delta p(x)=p_{0} \frac{\gamma M^{2} F(\chi)}{(2 \beta r)^{1 / 2}}
$$

where $\delta p=p-p_{0}, p_{0}$ is the ambient pressure, $\gamma$ is the ratio of specific heat, $M$ is the flight Mach number, $r$ is the radius in polar coordinate.

The sonic boom propagates method is the waveform parameter method [31]. This method is based on geometrical acoustics and calculates the sonic boom signature directly with distance steps along a ray, which is more suitable for automatic computation. It is reprogrammed in JAVA and implemented as a special module method. A weakness of the method is that the code expects one shock formation or coalescence at a time. For a complex signature with large numbers of points specified, there is a big chance of failure. This becomes a problem when using CFD data as Ffunction inputs. 


\section{Conceptual Design Concepts}

This part introduces the conceptual design concepts of a supersonic demonstrator, a supersonic business jet and a supersonic airliner. The results are arranged in a comparison pattern so that the readers can get intuitions among different concepts.

\section{A. Design Mission}

The design mission specifies the flight requirements for designs. These requirements are derived from the market or customer specifications. The mission requirements, shown in Table 1, for supersonic transport have been analysed by the authors in a review paper [5], considering the environmental impacts, technological challenges, and market analysis.

Table 1 Mission requirements for the designs

\begin{tabular}{|c|c|c|c|}
\hline Operational Specification & $\begin{array}{c}\text { Supersonic } \\
\text { Demonstrator }\end{array}$ & $\begin{array}{c}\text { Supersonic } \\
\text { Business Jet }\end{array}$ & $\begin{array}{l}\text { Supersonic } \\
\text { Airliner }\end{array}$ \\
\hline Design Range & $1,500 \mathrm{~nm}$ & $4,000 \mathrm{~nm}$ & $4,500 \mathrm{~nm}$ \\
\hline Design Cruise Speed & 1.4 Mach & 1.8 Mach & 1.8 Mach \\
\hline Maximum Cruise Altitude & $55,000 \mathrm{ft}$ & $55,000 \mathrm{ft}$ & $55,000 \mathrm{ft}$ \\
\hline Take-off Field Length & $1,500 \mathrm{~m}$ & $1,800 \mathrm{~m}$ & $2,000 \mathrm{~m}$ \\
\hline Landing Field Length & $1,000 \mathrm{~m}$ & $1,200 \mathrm{~m}$ & $1,500 \mathrm{~m}$ \\
\hline \multicolumn{4}{|l|}{ Environmental Specification } \\
\hline Sonic Boom intensity & $<0.5 \mathrm{psf}$ & $<1.0 \mathrm{psf}$ & $<1.5 \mathrm{psf}$ \\
\hline \multicolumn{4}{|l|}{ Dimensions } \\
\hline Wing Span & $8.483 \mathrm{~m}$ & $14.605 \mathrm{~m}$ & $18.811 \mathrm{~m}$ \\
\hline Wing Gross Area & $53 \mathrm{~m}^{2}$ & $154 \mathrm{~m}^{2}$ & $251 \mathrm{~m}^{2}$ \\
\hline Leading-edge sweep (inboard) & $75.5^{\circ}$ & $75.5^{\circ}$ & $75.5^{\circ}$ \\
\hline Leading-edge sweep (outboard) & $70^{\circ}$ & $70^{\circ}$ & $70^{\circ}$ \\
\hline Fuselage Overall Length & $28.600 \mathrm{~m}$ & $45.670 \mathrm{~m}$ & $61.100 \mathrm{~m}$ \\
\hline Fuselage maximum Width & $1.030 \mathrm{~m}$ & $1.980 \mathrm{~m}$ & $2.200 \mathrm{~m}$ \\
\hline \multicolumn{4}{|l|}{ Capacities } \\
\hline Maximum Take-off Mass & $9,291 \mathrm{~kg}$ & $45,000 \mathrm{~kg}$ & $78,000 \mathrm{~kg}$ \\
\hline Maximum Landing Mass & $7,433 \mathrm{~kg}$ & $36,000 \mathrm{~kg}$ & $62,400 \mathrm{~kg}$ \\
\hline Maximum Zero-Fuel Mass & $6,235 \mathrm{~kg}$ & $19,990 \mathrm{~kg}$ & $38,572 \mathrm{~kg}$ \\
\hline Operating Empty Mass & $5,963 \mathrm{~kg}$ & $17,990 \mathrm{~kg}$ & $32,322 \mathrm{~kg}$ \\
\hline Design Payload & $272 \mathrm{~kg}$ & $1,250 \mathrm{~kg}$ & $5,750 \mathrm{~kg}$ \\
\hline Crew + Passenger & $1+0$ & $2+10$ & $4+50$ \\
\hline \multicolumn{4}{|l|}{ Propulsion } \\
\hline Power Plant & $\begin{array}{l}1 \text { Mixed Flow Low- } \\
\text { Bypass Turbofan }\end{array}$ & $\begin{array}{l}2 \text { Mixed Flow Low- } \\
\text { Bypass Turbofan }\end{array}$ & $\begin{array}{l}2 \text { Mixed Flow Low- } \\
\text { Bypass Turbofan }\end{array}$ \\
\hline Sea Level Static T/O Thrust & $55 \mathrm{kN}$ & $110 \mathrm{kN}$ & $225 \mathrm{kN}$ \\
\hline
\end{tabular}

\section{B. General Geometry}

The authors have analysed several different wing and fuselage combinations in a previous study [1] and find that a low-boom low-drag design should have uniform longitudinal volume and lift distributions. The fuselage is expected to be more slender and a highly-swept wing is expected to flat the lift distribution. Horizontal tail is preferred rather than the canard because horizontal tail can help to reduce sonic boom signature in the aft part. The design of the supersonic demonstrator (Fig. 2) is based on the NASA X-59 concept. The SSBJ (Fig. 3) and supersonic airliner (Fig. 4) share the same wing shape with the demonstrator. The fuselage is optimized to not only meet the requirements of passenger comfortability and packaging requirement, but also for low-boom and low-drag objectives. 


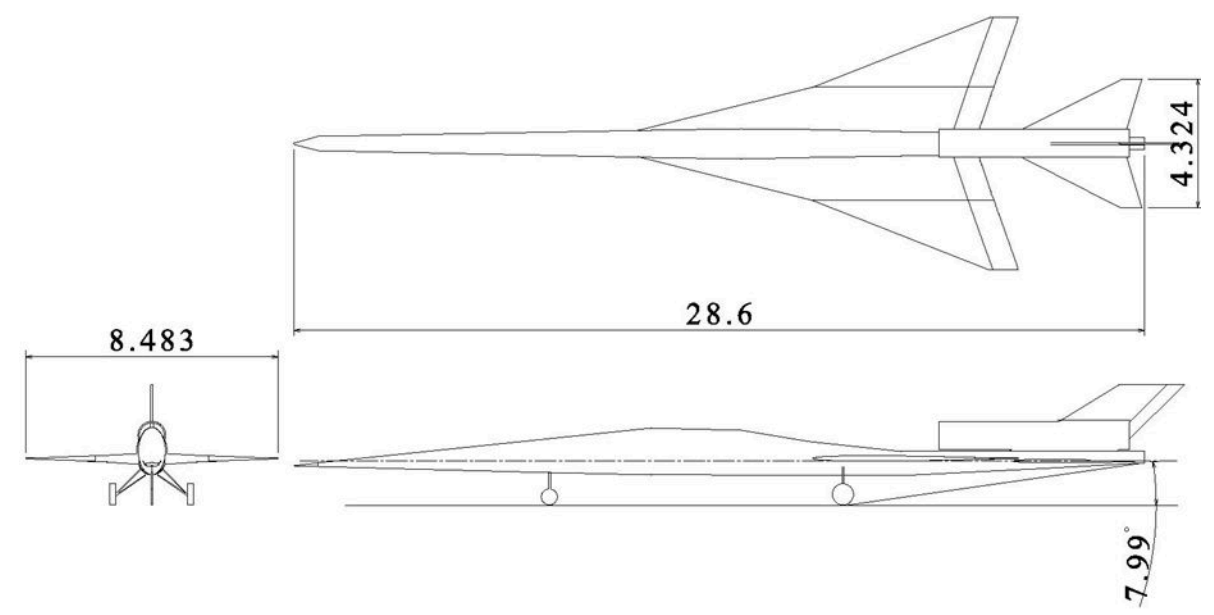

Fig. 2 General geometry of the supersonic demonstrator design

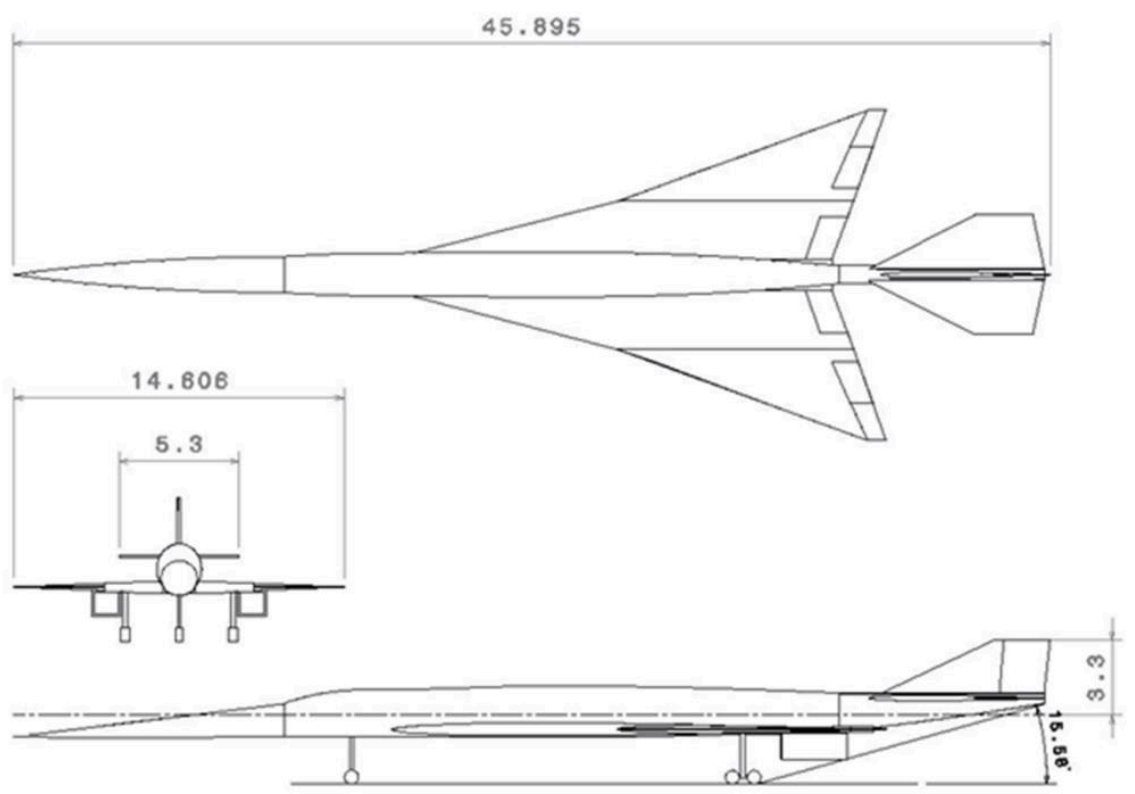

Fig. 3 General geometry of the SSBJ design 


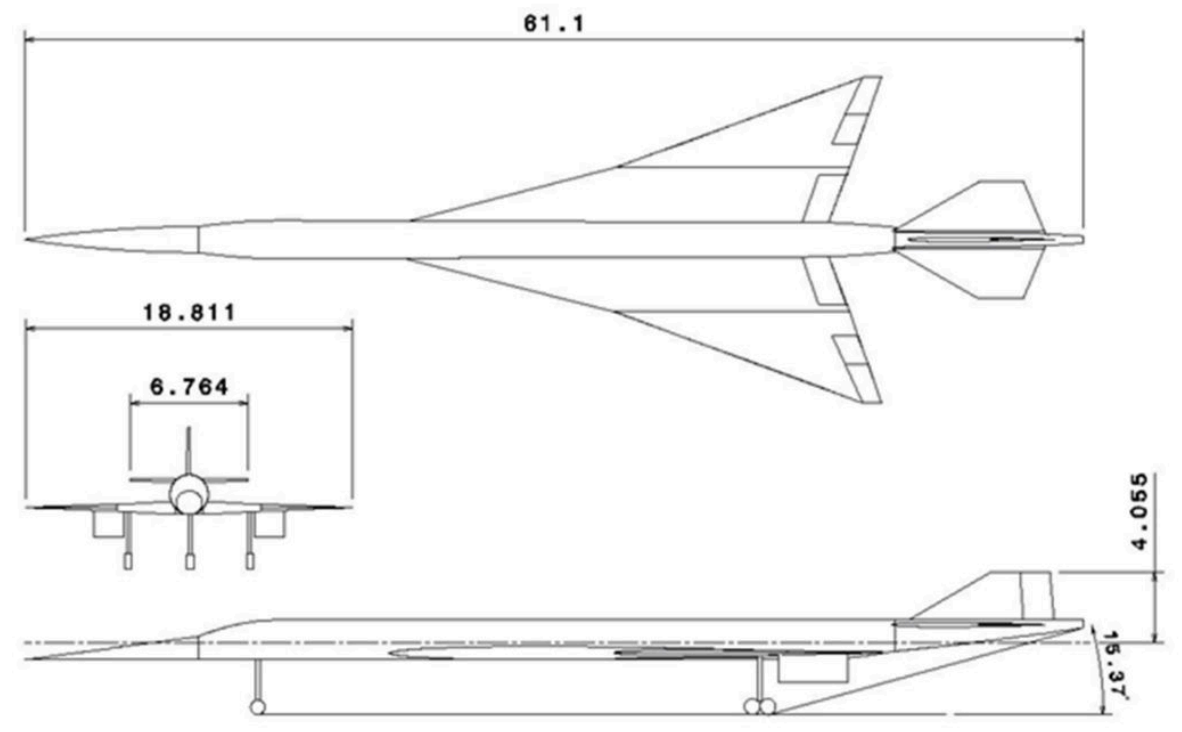

Fig. 4 General geometry of the supersonic airliner design

\section{Packaging}

Unlike the subsonic aircraft, the supersonic aircraft have very thin wings. The wing tank volume is usually not enough for mission fuel. Fuselage fuel tanks are required. Packaging is an important aspect of supersonic aircraft fuselage volume allocation. On the one hand, the supersonic wave drag reduction tends to an area-ruled fuselage. On the other hand, the passenger cabin and the fuselage fuel tanks require large blocks of volume. One of the most important function of the packaging is to check the available wing tank volume and arrange the fuselage fuel tanks to avoid interface with other inner components. The trim fuel tanks are also designed to control the centre of gravity directly. As can be found from Fig. 5, the packaging challenge for the supersonic demonstrator is relatively weak without a passenger cabin. On the other hand, it is very challenging for the supersonic airliner to achieve an area-ruled fuselage, as shown in Fig. 7.

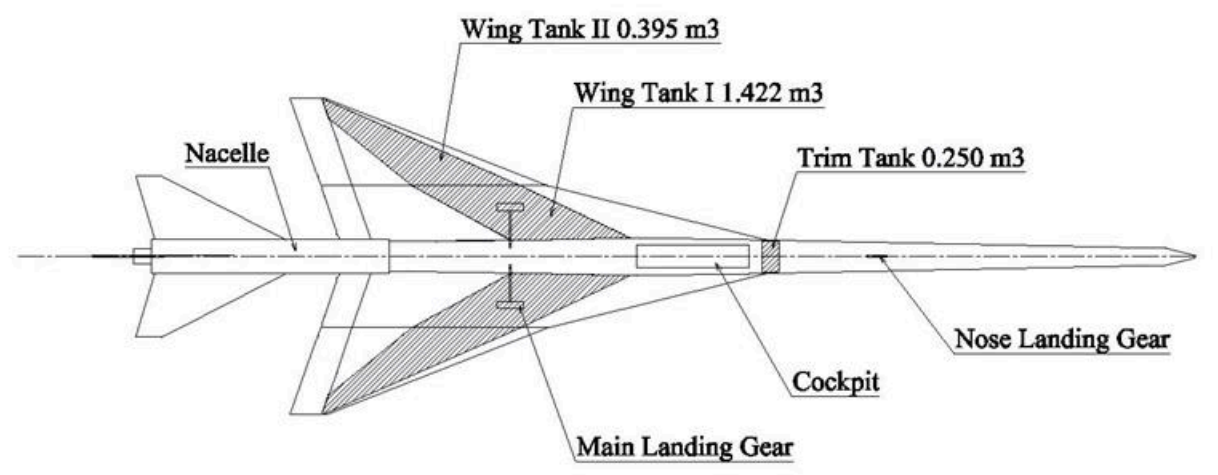

Fig. 5 Packaging of the supersonic demonstrator design 


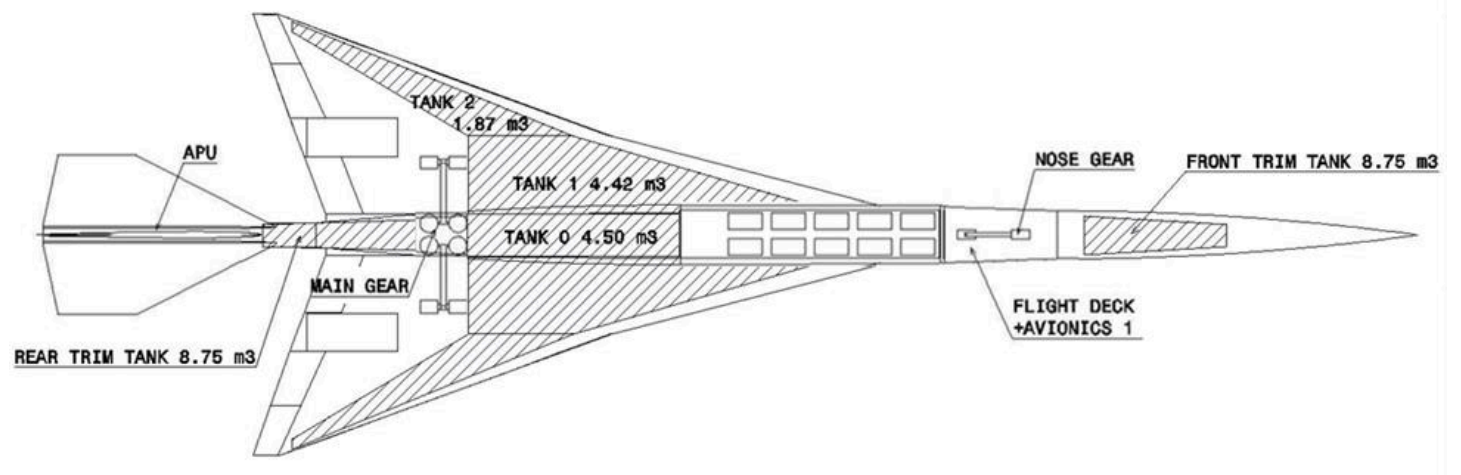

Fig. 6 Packaging of the SSBJ design

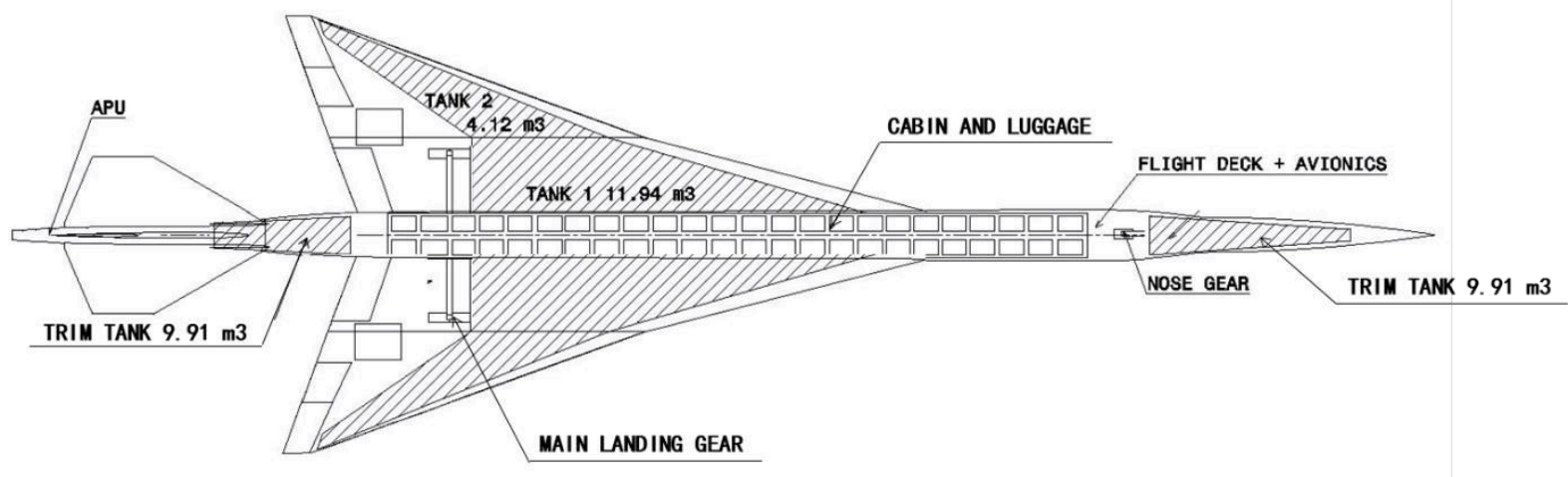

Fig. 7 Packaging of the supersonic airliner design

\section{Aerodynamics}

The aerodynamic coefficients are important for the performance estimation in the conceptual phase. For the supersonic aircraft, the low-drag optimizations mainly focus on decreasing the supersonic wave drag through geometry variation. Therefore, the supersonic cruise efficiencies (demonstrator $\mathrm{L} / \mathrm{D}=12.17$, SSBJ L/D $=10.77$, airliner $\mathrm{L} / \mathrm{D}=11.89$ ) of these concepts (with nacelles) are higher than the last-generation supersonic transport (e.g. Concorde $\mathrm{L} / \mathrm{D}=7$ )

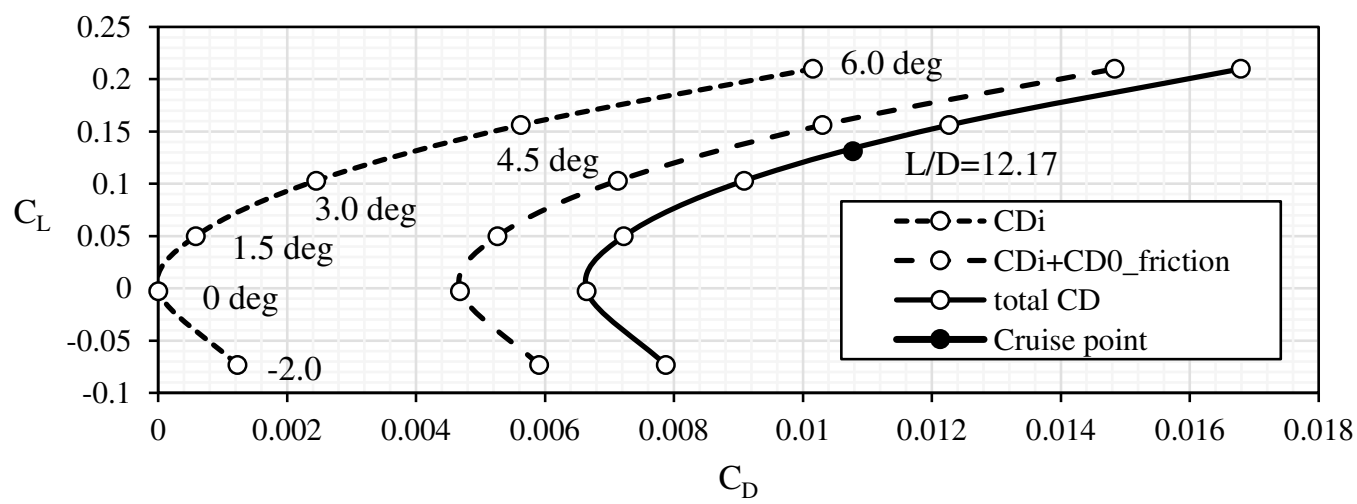

Fig. 8 Supersonic demonstrator drag components and drag polar 


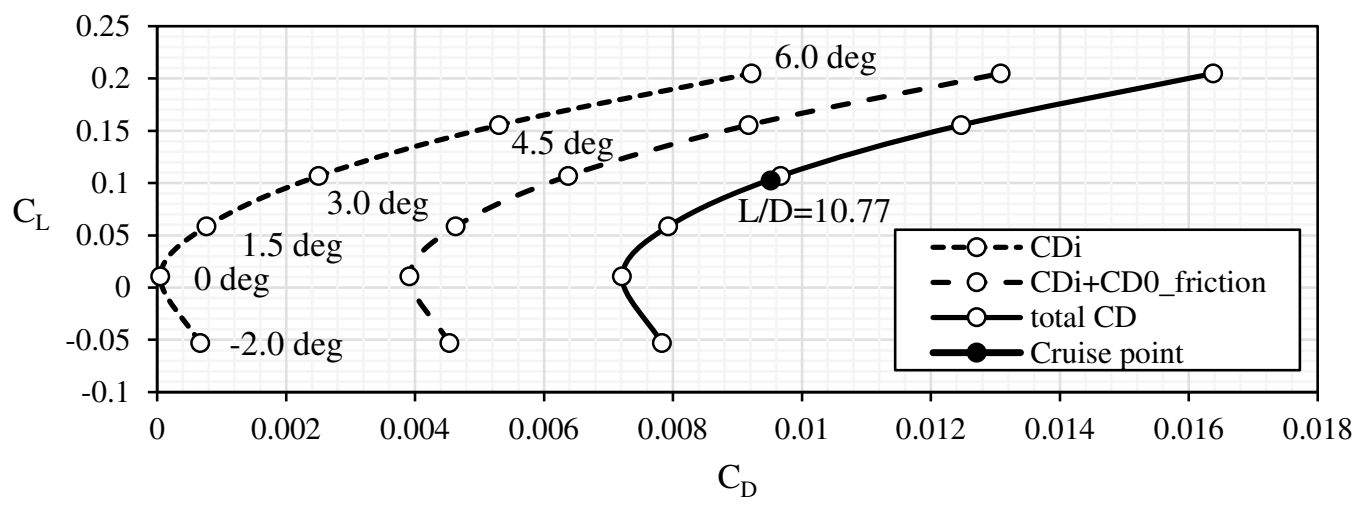

Fig. 9 SSBJ drag components and drag polar

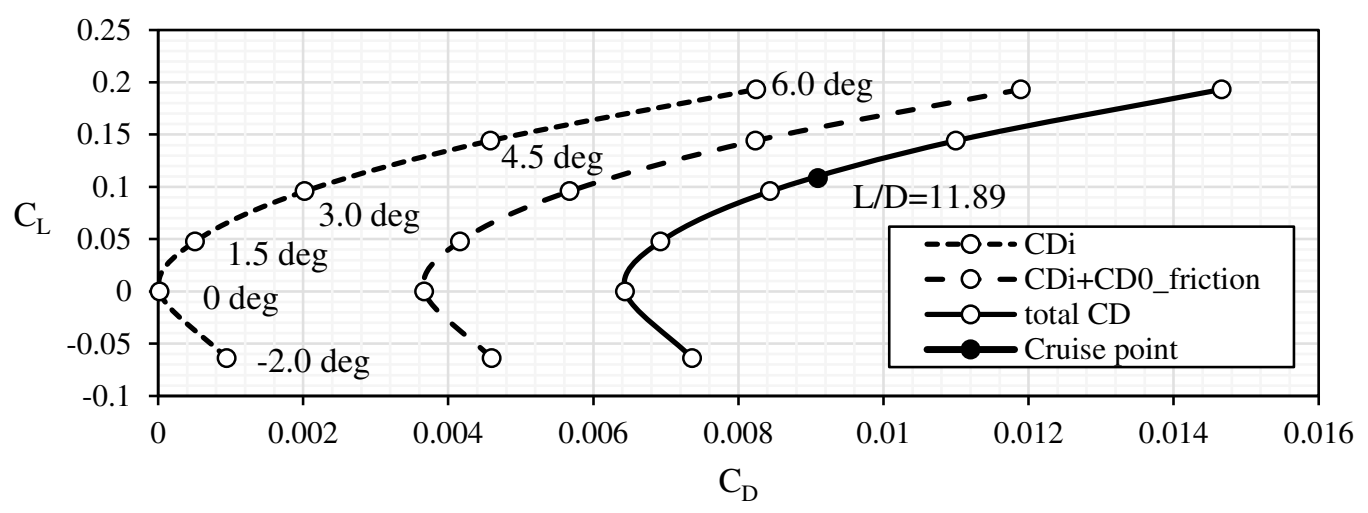

Fig. 10 Supersonic airliner drag components and drag polar

\section{E. Sonic Boom Intensity}

The idea of low-boom optimization is to tailor the lift and volume distribution to achieve a low near-field pressure, thus a low ground signature. As can be found in Fig. 11 and Fig. 12, the near-field signatures are optimized to have no single highest peak, especially the overpressure. The sonic boom intensity for the three concepts (without nacelles) are $0.47 \mathrm{psf}, 0.90 \mathrm{psf}$ and $1.08 \mathrm{psf}$, respectively.
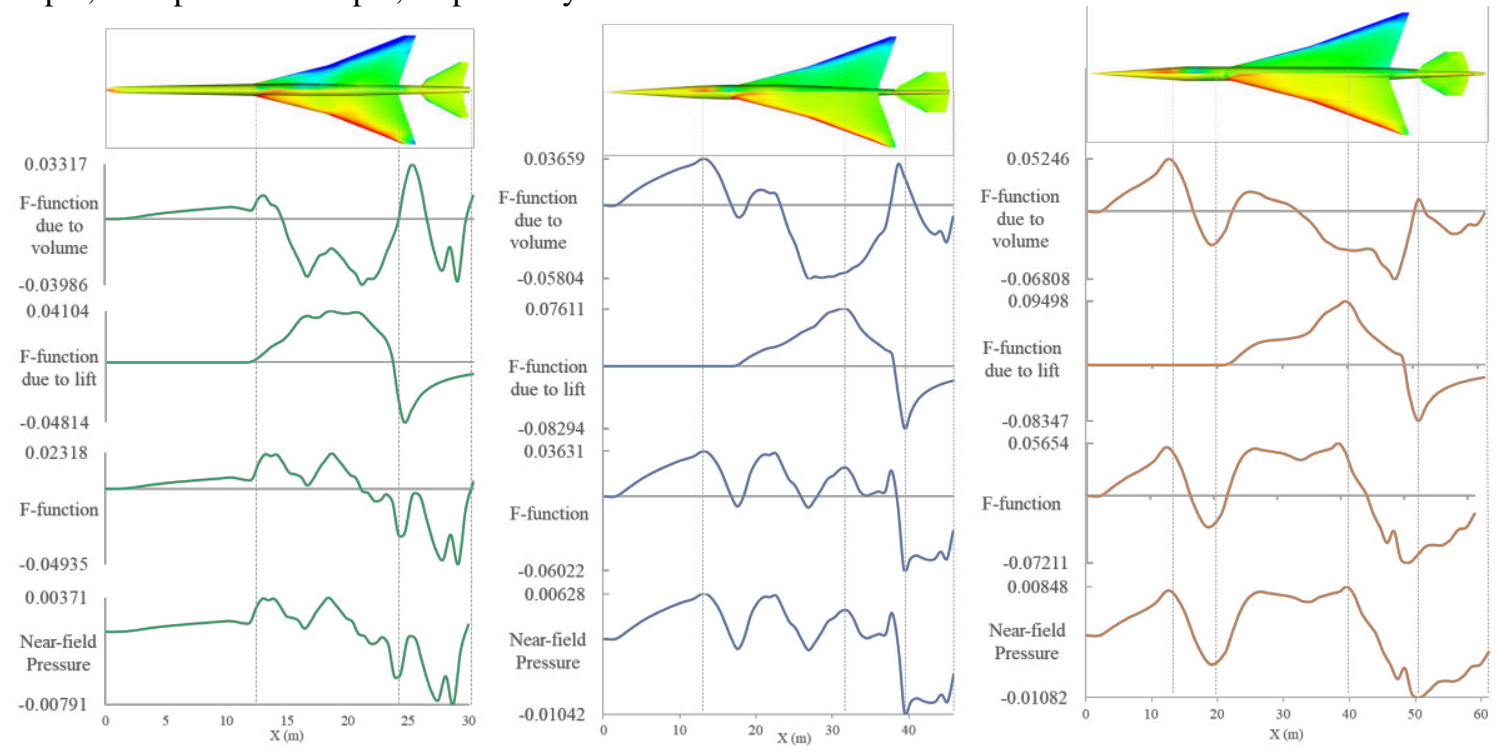

Fig. 11 Sonic boom near-field pressure generation 


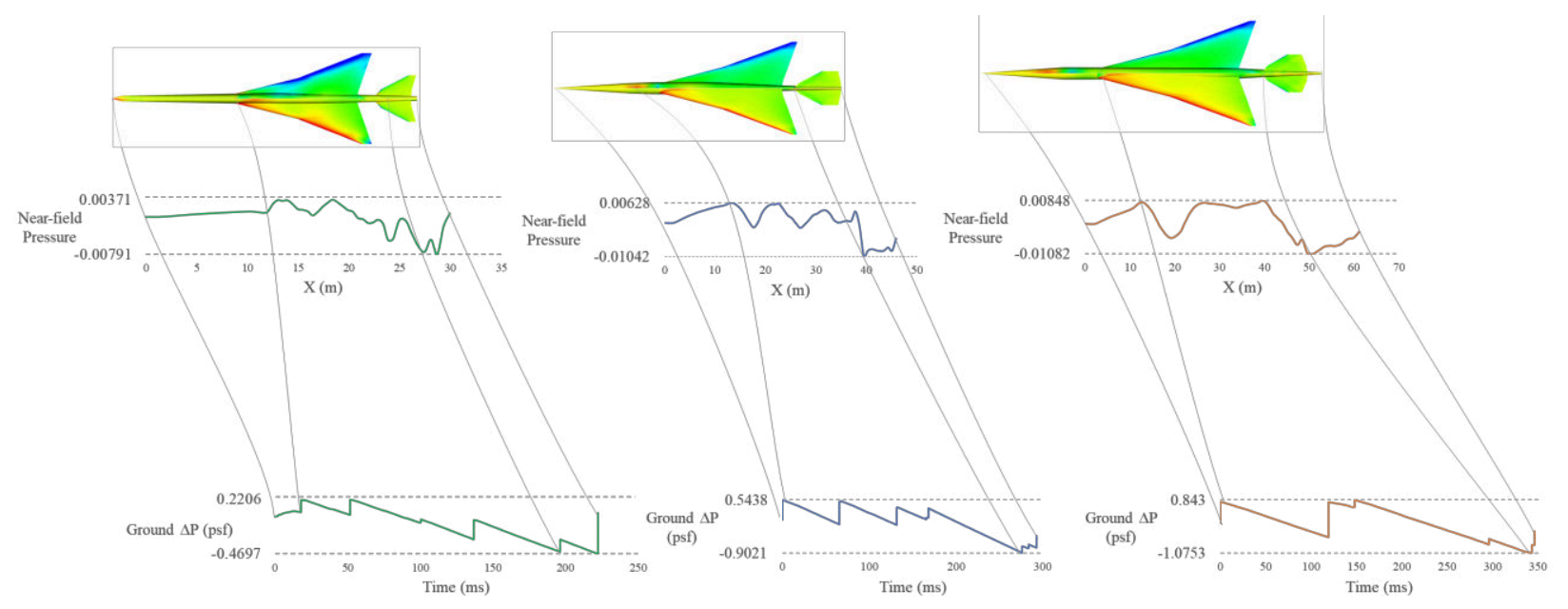

Fig. 12 Sonic boom propagation

\section{Conclusion}

Through the study, we demonstrate a supersonic transport model in a multidisciplinary design analysis and optimization environment. With this model, the design space of the low-boom low-drag SSBJ and supersonic airliner are explored.

As a result of the small wing and fuselage volume, the packaging design for supersonic aircraft is much more challenging than subsonic aircraft. The low-boom and low-drag constraints add difficulty to the design.

A single-seat supersonic demonstrator is designed in a multidisciplinary view and optimized for low sonic boom and low supersonic drag. The sonic boom intensity of this design is $0.47 \mathrm{psf}$. The supersonic lift to drag ratio is 12.17 . A 10-passenger SSBJ concept is designed and optimized following the same procedure. The sonic boom intensity of this design is optimized to be $0.90 \mathrm{psf}$. The supersonic cruise lift to drag ratio is 10.77 . For the 50-passenger supersonic airliner, the sonic boom intensity is $1.08 \mathrm{psf}$ and the supersonic cruise lift to drag ratio is 11.89 .

However, the low-boom optimization for supersonic aircraft with nacelles is still very challenging. The relatively bulky volume of the nacelles has a huge impact on the volume distribution, thus the sonic boom intensity. More efforts are required to study the low-boom design with nacelles or to study supersonic configurations with distributed propulsion system.

\section{References}

[1] Sun, Y., and Smith, H. "Low-boom low-drag solutions through the evaluation of different supersonic business jet concepts," Aeronautical Journal, Vol. 124, No. 1271, 2019, pp. 76-95. doi: 10.1017/aer.2019.131

[2] "Commercial Supersonic Technology: The Way Ahead," 2001

[3] NASA's Experimental Supersonic Aircraft Now Known as X-59 QueSST, https://www.nasa.gov/aero/nasaexperimental-supersonic-aircraft-x-59-quesst [retrieved 29 November 2019]

[4] This tiny supersonic jet could be the next generation Concorde, http://www.theverge.com/2016/11/15/13629104/boom-supersonic-jet-prototype-unveil-concorde [retrieved 11 December 2019]

[5] Sun, Y., and Smith, H. "Review and Prospect of Supersonic Business Jet Design," Progress in Aerospace Sciences, Vol. 90, 2017, pp. 12-38. doi: 10.1016/j.paerosci.2016.12.003

[6] Liebhardta, B., Lütjensb, K., Tracyc, R. R., and Haasd, A. O. "Exploring the Prospect of Small Supersonic Airliners-A Business Case Study Based on the Aerion AS2 Jet," 17th AIAA Aviation Technology, Integration, and Operations Conference, Denver, Colorado, 2017.

[7] Spike Aerospace, http://www.spikeaerospace.com/ [retrieved 20 September 2016]

[8] Torenbeek, E., Jesse, E., and Laban, M. "Conceptual Design and Analysis of a Mach 1.6 Airliner," 10th AIAA/ISSMO Multidisciplinary Analysis and Optimization Conference, Albany, New York, 2004, pp. AIAA 2004-4541. 
[9] Mack, R. J., "A Supersonic Business-Jet Concept Designed for Low Sonic Boom," NASA/TM-2003-212435, 2003

[10] Rallabhandi, S. K., and Mavris, D. N. "Design and analysis of supersonic business jet concepts," Proc of the 6th Aviation Technology, Integration and Operations (ATIO) Forum, No AIAA, 2006.

[11] Ordaz, I., Geiselhart, K. A., and Fenbert, J. W. "Conceptual Design of Low-Boom Aircraft with Flight Trim Requirement," Journal of Aircraft, Vol. 52, No. 3, 2015, pp. 932-939. doi: 10.2514/1.C033160

[12] Boom Technology, http://boom.aero/ [retrieved May 4 2020]

[13] Ueno, A., Watanabe, Y., Salah El Din, I., Grenon, R., and Carrier, G. "Low Boom/Low Drag Small Size Supersonic Aircraft Design," VII European Congress on Computational Methods in Applied Sciences and Engineering. 2016.

[14] Sun, Y., and Smith, H. "Supersonic Business Jet Conceptual Design in a Multidisciplinary Design Analysis Optimization Environment," 2018 AIAA/ASCE/AHS/ASC Structures, Structural Dynamics, and Materials Conference, Kissimmee, Florida, 2018.

[15] Sun, Y., and Smith, H. "Sonic Boom and Drag Evaluation of Supersonic Jet Concepts," 2018 AIAA/CEAS Aeroacoustics Conference, Georgia, Atlanta, 2018.

[16] Sun, Y., and Smith, H. "Low-boom low-drag optimization in a multidisciplinary design analysis optimization environment," Aerospace Science and Technology, Vol. 94, 2019, p. 105387. doi: 10.1016/j.ast.2019.105387

[17] Smith, H., Sziroczák, D., Abbe, G. E., and Okonkwo, P. "The GENUS Aircraft Conceptual Design Environment," Proceedings of the Institution of Mechanical Engineers, Part G: Journal of Aerospace Engineering, Vol. 233, No. 8, 2018, pp. 2932-2947. doi: $10.1177 / 0954410018788922$

[18] Abbe, G. E. "Conceptual Design Methodologies for Small Solar Powered Unmanned Aerial Vehicle," Ph.D., School of Aerospace Transport and Manufacturing, Cranfield University, Bedford, UK, 2015

[19] Sziroczak, D. "Conceptual Design Methodologies Appropriate to Hypersonic Space and Global Transportation Systems," Ph.D., School of Aerospace Transport and Manufacturing, Cranfield University, Bedford, UK, 2015

[20] Okonkwo, P. P. C. "Conceptual Design Methodology for Blended Wing Body Aircraft," Ph.D., School of Aerospace Transport and Manufacturing, Cranfield University, Bedford, UK, 2016

[21] Sun, Y., and Smith, H. "Turbofan Airliner Conceptual Design in Multidisciplinary Design Analysis Optimization Environment," 1st International Conference in Aerospace for Young Scientists, Beijing, P.R.China, 2016.

[22] Sepulveda, E., Smith, H., and Sziroczak, D. "Multidisciplinary Analysis of Subsonic Stealth Unmanned Combat Aerial Vehicles," CEAS Aeronautical Journal, Vol. 10, 2018, pp. 431-442. doi: 10.1007/s13272-018-0325-0

[23] Howe, D. Aircraft conceptual design synthesis, Professional Engineering Publishing, 2000.

[24] Raymer, D. P. Aircraft Design: A Conceptual Approach, Sixth Edition, AIAA, Inc., Reston, VA, 2018.

[25] Saaris, G. R., Tinoco, E., Lee, J., and Rubbert, P., "A502I User's Manual-PAN AIR Technology Program for Solving Problems of Potential Flow about Arbitrary Configurations," Boeing Document, 1992

[26] Gur, O., Mason, W. H., and Schetz, J. A. "Full-Configuration Drag Estimation," Journal of Aircraft, Vol. 47, No. 4, 2010, pp. 1356-1367. doi: $10.2514 / 1.47557$

[27] Harris, R. V., "An Analysis and Correlation of Aircraft Wave Drag," NASA TM X-947, 1964

[28] EngineSim Version 1.8a, https://www.grc.nasa.gov/www/k-12/airplane/ngnsim.html [retrieved 21 December 2019]

[29] Williams, J. E., and Vukelich, S. R., "The USAF stability and control digital DATCOM," AFFDL-TR-793032, 1979

[30] Whitham, G. "The Flow Pattern of A Supersonic Projectile," Communications on Pure and Applied Mathematics, Vol. 5, No. 3, 1952, pp. 301-348. doi: 10.1002/cpa.3160050305

[31] Thomas, C. L., "Extrapolation of Sonic Boom Pressure Signatures by the Waveform Parameter Method," NASA TN D-6832, 1972 


\section{Cranfield University}

2020-06-08

\section{Conceptual design of low-boom \\ low-drag supersonic transports}

Sun, Yicheng

AIAA

Sun Y, Smith H, Chen H. (2020) Conceptual design of low-boom low-drag supersonic transports. In: AIAA Aviation 2020 Forum, Virtual Event, 15-19 June 2020

https://doi.org/10.2514/6.2020-2635

Downloaded from Cranfield Library Services E-Repository 